\title{
Two insulin gene single nucleotide polymorphisms associated with type 1 diabetes risk in the Finnish and Swedish populations
}

\author{
Antti-Pekka Laine ${ }^{\mathrm{a}, *}$, Hanna Holmberg ${ }^{\mathrm{c}}$, Anita Nilsson ${ }^{\mathrm{d}}$, Eva Örtqvist ${ }^{\mathrm{e}}$, Minna Kiviniemi ${ }^{\mathrm{a}}$, \\ Outi Vaarala $^{\mathrm{c}, \mathrm{f}}$, Hans K. Åkerblom ${ }^{\mathrm{g}}$, Olli Simell ${ }^{\mathrm{b}}$, Mikael Knip ${ }^{\mathrm{g}, \mathrm{h}}$, Johnny Ludvigsson ${ }^{\mathrm{c}}$, \\ Sten-A Ivarsson ${ }^{\mathrm{d}}$, Karin Larsson ${ }^{\mathrm{d}}$, Åke Lernmark ${ }^{\mathrm{d}}$, Jorma Ilonen ${ }^{\mathrm{a}, \mathrm{i}}$ and \\ the Finnish Paediatric Diabetes Registry \\ ${ }^{a}$ Immunogenetics Laboratory, University of Turku, Turku, Finland \\ ${ }^{\mathrm{b}}$ Department of Paediatrics, University of Turku, Turku, Finland \\ ${ }^{\mathrm{c}}$ Department of Molecular and Clinical Medicine, Linköping University, Linköping, Sweden \\ ${ }^{\mathrm{d}}$ Department of Endocrinology and Paediatrics, University Hospital Malmö, University of Lund, Lund, Sweden \\ 'Astrid Lindgren's Children Hospital, Karolinska Hospital, Stockholm, Sweden \\ ${ }^{\mathrm{f}}$ Department of Viral Diseases and Immunology, National Public Health Institute, Helsinki, Finland \\ ${ }^{\mathrm{g}}$ Hospital for Children and Adolescents, University of Helsinki, Helsinki, Finland \\ ${ }^{\mathrm{h}}$ Department of Pediatrics, Tampere University Hospital, Tampere, Finland \\ ${ }^{\mathrm{i}}$ Department of Clinical Microbiology, University of Kuopio, Kuopio, Finland
}

\begin{abstract}
We have developed high-throughput tests for the detection of the insulin gene region SNPs $-23 \mathrm{HphI}$ and $-2221 \mathrm{MspI}$. The potential of these markers to enhance the efficiency of type 1 diabetes risk screening was then evaluated by analyzing them in Finnish and Swedish populations. Blood spots on filter paper were analyzed using PCR followed by sequence-specific hybridization and time-resolved fluorometry reading. Distribution of the genotypes at both positions differed significantly among the affected children compared to the controls. The risk genotypes (CC, AA) were significantly more common in Finland than in Sweden, both among patients and controls. The VNTR genotype homozygous for the protective class III alleles showed a significantly stronger protective effect than the heterozygote $(p=0.02)$. Analyzing both SNPs enabled the detection of VNTR class III subclasses IIIA and IIIB. The observed significance between effects of the protective genotypes was due to the strong protective effect of the IIIA/IIIA genotype. IIIA/IIIA was the only genotype with significant discrepancy between protective effects compared to the other class III genotypes. These observations suggest that heterogeneity between the protective IDDM2 lineages could exist, and analyzing both $-23 \mathrm{HphI}$ and $-2221 \mathrm{MspI}$ would thus potentially enhance the sensitivity and specificity of type 1 diabetes risk estimation.
\end{abstract}

Keywords: Type 1 diabetes, insulin gene region, Finnish population, screening for genetic risk

${ }^{*}$ Corresponding author: Antti-Pekka Laine, University of Turku/Medicity, Tykistokatu 6a, FIN-20520, Finland. Tel.: +358 2 3337023; Fax: +358 2 3337000; E-mail: aplaine@utu.fi.

\section{Introduction}

Susceptibility to type 1 diabetes (T1D) is defined largely by genetic constitution. The major role of the HLA genes constituting approximately half of the 
genetic component has been known since the 1970s, whereas evidence for additional gene regions with a smaller contribution has only slowly accumulated. Among these "minor" regions is the insulin gene region (IDDM2). The contribution of the insulin gene region to T1D susceptibility has been widely studied and the effect of the polymorphisms upon disease risk within the region is well established, although their exact function in the disease aetiology is still to be unravelled. IDDM2 locus has been mapped to a VNTR (variable number of tandem repeat minisatellite) locus located 596 bp upstream of the insulin gene (INS) translation starting codon [1]. SNPs adjacent to VNTR were excluded as aetiological polymorphisms [1], but a recent association study of 177 polymorphisms in and around the IDDM2 region reinstated two SNPs, $-23 \mathrm{HphI}$ and $+1140 \mathrm{~A} / \mathrm{C}$, as potential candidates for causal variant [2].

VNTR consists of repeat units of 14-15 base pairs [3]. Class I VNTR alleles contain 28 to 44 repeats and class III alleles 138 to 159 repeats. Intermediate class II alleles are rare in non-African populations [4, 5].

As a group, class I alleles are associated with risk for T1D while class III alleles show a dominant protective effect, but both classes have individual alleles or subclasses with reportedly converse or neutral effects upon T1D risk [6,7]. Class I alleles are associated with significantly higher levels of insulin expression in the pancreas when compared to class III alleles [8,9]. Conversely, in thymus, the class III containing genotypes are associated with significantly higher levels of insulin expression (2 to 3 fold) than the class I homozygote. VNTR class-specific differences in thymic insulin expression is hypothesized to be the functional basis by which the IDDM2 locus affects T1D aetiology. Higher level of thymic insulin is assumed to lead to a better tolerance of insulin autoantigen and thus protection against T1D [10-12]. The mechanism by which VNTR allegedly regulates the levels of thymic insulin expression is unknown and the possibility that VNTR is simply a marker to adjacent functional polymorphism(s) has not been undeniably excluded.

SNPs $-23 \mathrm{HphI}$ and $+1140 \mathrm{~A} / \mathrm{C}$ are effectively in complete linkage disequilibrium (LD) with VNTR classes I and III [5], which allows them to be used as surrogate markers for VNTR classes. It is preferable to analyze the surrogate marker instead of the VNTR since genotyping the GC-rich VNTR minisatellite is a time-consuming technical challenge compared to the relatively mundane methods required to genotype the flanking SNPs.
Haplotypes of the VNTR class III alleles and neighbouring variations have been divided into two protective lineages, the protective haplotype $(\mathrm{PH})$ and the very protective haplotype (VPH) [1], which correspond to VNTR class III subclasses IIIA and IIIB respectively [6]. The protective effect of PH and VPH have been shown to differ significantly in earlier studies [1-14], but a recent study by Barratt et al., using several independent populations, was unable to find a significant discrepancy between the protective effects conferred by these haplotypes [2].

Haplotypes of the flanking SNPs can be used to make a distinction between IIIA and IIIB without analyzing VNTR directly. Genotyping -2221MspI in addition to $-23 \mathrm{HphI}$ allows the separation of the two subclasses with effective accuracy and reasonable ease [2-5]. Allele A of surrogate SNP - 23HphI denotes VNTR class I, and allele T class III. Allele C of -2221MspI represents VNTR class I or subclass IIIB, while the T allele represents subclass IIIA (in $98 \%$ of the lineages in the UK population) [5]. Consequently, VNTR class I is defined by SNPs - 2221MspI and -23HphI forming respective haplotype $\mathrm{C}-\mathrm{A}$, subclass IIIB (VPH) by haplotype $\mathrm{C}-\mathrm{T}$ and subclass IIIA (PH) by haplotype T-T.

We have previously demonstrated the apparent effect of the INS gene $-2221 \mathrm{MspI}$ polymorphism on the T1D risk in an extensive population-based series in Finland [15]. Since the VNTR class I associated $-2221 \mathrm{MspI} \mathrm{C}$ allele is also present in the protective class III haplotype, analyzing VNTR surrogate marker $-23 \mathrm{HphI}$ instead of $-2221 \mathrm{MspI}$ could enhance the sensitivity and specificity of IDDM2 in the T1D risk estimation. Also, if disparity in the levels of the protective effect from class III subclasses IIIA and IIIB exists, analyzing both markers would enable subclass separation and further enhance the accuracy of the T1D risk estimation.

For the purpose of evaluating the relative value of these markers in screening for the T1D risk, we have developed a high-throughput test for the detection of the $-23 \mathrm{HphI}$ polymorphism and analyzed these two insulin gene SNPs in the Finnish and Swedish populations.

\section{Subjects, materials and methods}

Samples were collected at paediatric centres treating children affected by T1D. All subjects with T1D were diagnosed under the age of 15 according to the 
WHO criteria. The study was approved by the Ethics Committees of the participating hospitals and informed consents were obtained from the study subjects and/or their parents. In 612 Finnish T1D families the affected child and both parents were genotyped. In each family, the parental haplotypes not transmitted to the affected child were used as affected family-based artificial controls (AFBAC) [16] and the transmitted haplotypes were considered as cases. The families were tested for inconsistencies between the parents and offspring with the PEDCHECK [17] program. Families showing possible non-paternity were removed from the AFBAC analysis.

The Finnish families with T1D originated from all around Finland. The Swedish cohorts were collected in Malmö (Southern Sweden): 142 children with T1D and 219 controls, and in Linköping (Southeastern Sweden): 77 children with T1D and 540 controls. An additional 138 children with T1D were sampled in Stockholm (Southeastern Sweden). All datasets were in Hardy-Weinberg equilibrium for both of the markers. The $-2221 \mathrm{MspI}--23 \mathrm{HphI}$ haplotypes were used to deduce the VNTR genotypes for each sample. Since parental data was not available for the Swedish cohorts, SNP haplotypes were constructed from the combined $-23 \mathrm{Hphi}--2221 \mathrm{MspI}$ genotypes. The haplotypes of combined genotypes were non-decipherable only in the combined heterozygote CT-AT. Fortunately, the haplotype which combines allele $\mathrm{T}$ at $-2221 \mathrm{MspI}$ and allele $\mathrm{A}$ at $-23 \mathrm{HphI}$ is extremely rare, so effectively the haplotypes for the CT-AT genotype were C-A and T-T.

All the Finnish samples and the Swedish samples from Linköping and Stockholm were analyzed using a sequence-specific oligonucleotide hybridization method based on lanthanide labeled probes. The Swedish samples from Malmö were analyzed with a hybridization method for the $-2221 \mathrm{MspI}$ and with a HphI digestion method [18] for the -23HphI.There were no significant or conspicuous differences between allele frequencies in the Swedish datasets analyzed by the different genotyping methods. The assay used in the analysis of the $-2221 \mathrm{MspI}$ polymorphism has been described in detail earlier [15]. For the $-23 \mathrm{HphI}$ assay, a circle of the blood spot was first incubated with sodium hydroxide and then neutralized with a Tris-Cl buffer. $20 \mu \mathrm{l}$ of extract containing genomic DNA was transferred into the amplification mixture. The biotinylated amplification product was hybridized with two oligonucleotide probes after denaturation (T probe: 5'-Europium-CTGTCTCCCAGA-3' and A probe: 5'-Terbium-CTGTCACCCAGA-3'). Primers used for the PCR amplification were: forward 5'CTGGGCTCGTGAAGCATGT-3' and 5' -biotinylated reverse 5'-GCATCCACAGGGCCATG-3'. The consistency of the genotyping method was validated by analyzing genotypic controls (genomic DNA) and nontemplate controls in each individual 96-plate run.

The statistical significance in distributions of genotypes between the groups was tested using the chisquare function of the Epistat software (Tracy L. Gustafson, Round Rock, TX, USA).

\section{Results}

Table 1 shows that both SNPs were associated with diabetes risk in Finland and Sweden. The odd ratios (OR) associated with the protective genotypes of the two SNPs were of the same magnitude in the Finnish and Swedish populations. For both SNPs, the VNTR class III homozygote (TT for both SNPs) showed a stronger protective effect than the heterozygote. This was true for both of the populations. The differences between protective effects for the heterozygote and homozygote were significant in the combined data sets of the Finnish and Swedish samples $(p=0.01$, OR $=$ 2.53 for the $-2221 \mathrm{MspI}, p=0.02$, OR $=1.87$ for the $-23 \mathrm{HphI})$.

Both risk genotypes were significantly more common in Finland than in Sweden. This was true for both patients and controls, although the difference was slightly more pronounced among the controls ( $p=$ 0.003 and 0.0003 for patients and controls respectively in $-2221 \mathrm{MspI}, p=0.0003$ and 0.0001 respectively in $-23 \mathrm{HphI})$. The combined homozygous protective genotype was twice as common in Sweden.

The combined $-2221 \mathrm{MspI}--23 \mathrm{HphI}$ genotypes and VNTR genotypes for patients and controls are shown in Table 2. As expected, the only genotype showing increased risk for T1D was VNTR class I/I genotype CC-AA. For both populations, the VNTR subclass IIIA homozygote showed the strongest protection for T1D; the odds ratios were 0.21 and 0.18 respectively for Finland and Sweden. The protective effect of the I/IIIA heterozygote was noticeably weaker than the effect of IIIA/IIIA in both populations and significantly weaker when the combined dataset was analyzed (Table 3). The difference between the effects of the subclass IIIB heterozygote and homozygote could not be tested reliably because the IIIB/IIIB genotype was rare in both populations, but the comparison in the combined datasets seems to suggest that subclass 
Table 1

Genotype distributions of two single nucleotide polymorphisms in the insulin gene region among Finnish and Swedish children with type 1 diabetes (T1D) and controls (cont) and respective VNTR genotypes. $\mathrm{P}$ values are calculated for the difference in genotype distribution between cases and controls using predisposing $\mathrm{CC}$ or AA genotypes as a reference $(\mathrm{OR}=$ Odds ratio. $95 \% \mathrm{CI}=95 \%$ confidence interval $)$

\begin{tabular}{|c|c|c|c|c|c|c|c|c|}
\hline Finland & & & & & & & & \\
\hline$-2221 \mathrm{MspI}$ & VNTR genotype & T1D & $\%$ & cont & $\%$ & p-value & OR & $95 \% \mathrm{CI}$ \\
\hline $\mathrm{CC}$ & I/I or I/III & 515 & 84.8 & 418 & 68.9 & & 1.0 & \\
\hline $\mathrm{CT}$ & I/III or III/III & 88 & 14.5 & 174 & 28.7 & $<1.0 \mathrm{E}-6$ & 0.41 & $0.30-0.55$ \\
\hline TT & III/III & 4 & 0.7 & 15 & 2.5 & 0.006 & 0.22 & $0.06-0.70$ \\
\hline sum & & 607 & & 607 & & & & \\
\hline$-23 \mathrm{HphI}$ & & T1D & $\%$ & cont & $\%$ & p-value & OR & $95 \% \mathrm{CI}$ \\
\hline AA & $\mathrm{I} / \mathrm{I}$ & 483 & 79.6 & 362 & 59.6 & & 1.0 & \\
\hline $\mathrm{AT}$ & I/III & 115 & 18.9 & 218 & 35.9 & $<1.0 \mathrm{E}-6$ & 0.40 & $0.30-0.52$ \\
\hline TT & III/III & 9 & 1.5 & 27 & 4.4 & 0.0003 & 0.25 & $0.11-0.56$ \\
\hline sum & & 607 & & 607 & & & & \\
\hline \multicolumn{9}{|l|}{ Sweden } \\
\hline$-2221 \mathrm{MspI}$ & & T1D & $\%$ & cont & $\%$ & p-value & OR & $95 \% \mathrm{CI}$ \\
\hline $\mathrm{CC}$ & I/I or I/III & 272 & 76.2 & 454 & 59.8 & & 1.0 & \\
\hline $\mathrm{CT}$ & I/III or III/III & 80 & 22.4 & 261 & 34.4 & $7.8 \mathrm{E}-6$ & 0.51 & $0.38-0.69$ \\
\hline TT & III/III & 5 & 1.4 & 44 & 5.8 & 0.0002 & 0.19 & $0.07-0.51$ \\
\hline sum & & 357 & & 759 & & & & \\
\hline$-23 \mathrm{HphI}$ & & T1D & $\%$ & cont & $\%$ & p-value & OR & $95 \% \mathrm{CI}$ \\
\hline AA & $\mathrm{I} / \mathrm{I}$ & 244 & 68.3 & 380 & 50.1 & & 1.0 & \\
\hline AT & I/III & 101 & 28.3 & 310 & 40.8 & $1.3 \mathrm{E}-6$ & 0.51 & $0.38-0.68$ \\
\hline TT & III/III & 12 & 3.4 & 69 & 9.1 & $3.2 \mathrm{E}-5$ & 0.27 & $0.14-0.53$ \\
\hline sum & & 357 & & 759 & & & & \\
\hline \multicolumn{9}{|c|}{ Finland+Sweden } \\
\hline$-2221 \mathrm{MspI}$ & & T1D & $\%$ & cont & $\%$ & p-value & OR & $95 \% \mathrm{CI}$ \\
\hline $\mathrm{CC}$ & I/I or I/III & 787 & 81.7 & 872 & 63.8 & & 1.0 & \\
\hline CT & I/III or III/III & 168 & 17.4 & 435 & 31.9 & $<1.0 \mathrm{E}-6$ & 0.43 & $0.35-0.53$ \\
\hline $\mathrm{TT}$ & III/III & 9 & 0.9 & 59 & 4.3 & $<1.0 \mathrm{E}-6$ & 0.17 & $0.08-0.36$ \\
\hline sum & & 964 & & 1366 & & & & \\
\hline$-23 \mathrm{HphI}$ & & T1D & $\%$ & cont & $\%$ & $\mathrm{p}$-value & OR & $95 \% \mathrm{CI}$ \\
\hline $\mathrm{AA}$ & $\mathrm{I} / \mathrm{I}$ & 727 & 75.4 & 742 & 54.3 & & 1.0 & \\
\hline AT & I/III & 216 & 22.4 & 528 & 38.7 & $<1.0 \mathrm{E}-6$ & 0.42 & $0.34-0.51$ \\
\hline $\mathrm{TT}$ & III/III & 21 & 2.2 & 96 & 7.0 & $<1.0 \mathrm{E}-6$ & 0.22 & $0.13-0.37$ \\
\hline sum & & 964 & & 1366 & & & & \\
\hline
\end{tabular}

IIIB conveys a weaker protective effect than subclass IIIA (Tables 2 and 3). This was further demonstrated by the non-significant difference between the protective effects of I/IIIA and IIIA/IIIB and by the clear (although non-significant) difference between the effects of IIIA/IIIB and IIIA/IIIA $(\mathrm{OR}=1.84)$ (Table 3$)$.

\section{Discussion}

Our study confirms that type 1 diabetes risk is associated with homozygosity for the class I VNTR haplotypes within the insulin gene region. Heterozygotes carrying either IIIA (T-T) or IIIB (C-T) haplotypes with a class I haplotype both had a significantly lower risk of developing T1D than the class I homozygote in the Finnish and Swedish populations. As both class III haplotypes are characterized by a $\mathrm{T}$ allele at $-23 \mathrm{HphI}$, this
SNP is an optimal choice for the purpose of simple diabetes risk screening and the method we developed for defining the alleles offers an option for a rapid screening assay. The developed method applies the general principles we have used in high-throughput genetic tests for screening T1D susceptibility in the general population. These tests have been based on the amplification of polymorphic gene regions directly from blood spots on filter paper thus eliminating the laborious DNA extraction. This is followed by sequence-specific hybridization reactions performed in a microtitration plate format and a time-resolved fluorometry-based reading of hybridization reactions where the multiple lanthanide labels facilitate the simultaneous use of several probes in the same reaction $[19,20]$. We have earlier adopted this technology for the detection of the INS gene $-2221 \mathrm{MspI}$ single nucleotide polymorphism [15]. To maximize the simplicity of the new assay for $-23 \mathrm{HphI}$, 
Table 2

Combined genotypes for $-2221 \mathrm{MspI}$ and $-23 \mathrm{HphI}$ and their effect on diabetes risk in the Finnish. Swedish and combined populations. The VNTR genotypes are deduced from the $-2221 \mathrm{MspI}-$ $-23 \mathrm{HphI}$ haplotypes. P-values are calculated for the difference in genotype distribution between the T1D patients and controls using the predisposing CC-AA genotype as a reference (OR $=$ Odds ratio. $95 \% \mathrm{CI}=95 \%$ confidence interval. $\mathrm{ns}=$ non-significant)

\begin{tabular}{|c|c|c|c|c|c|c|c|c|}
\hline Finland & & & & & & & & \\
\hline Genotype & VNTR genot. & T1D & $\%$ & Controls & $\%$ & $\mathrm{p}$-value & OR & $95 \% \mathrm{CI}$ \\
\hline CC-AA & $\mathrm{I} / \mathrm{I}$ & 482 & 79.4 & 362 & 59.6 & & 1.00 & \\
\hline CC-AT & I/IIIB & 32 & 5.3 & 54 & 8.9 & 0.0006 & 0.44 & $0.27-0.72$ \\
\hline CC-TT & IIIB/IIIB & 1 & 0.2 & 2 & 0.3 & & & \\
\hline CT-AA & & 1 & 0.2 & 0 & 0 & & & \\
\hline CT-AT & I/IIIA & 83 & 13.7 & 163 & 26.9 & $<1.0 \mathrm{E}-6$ & 0.38 & $0.28-0.52$ \\
\hline CT-TT & IIIA/IIIB & 4 & 0.7 & 11 & 1.8 & 0.04 & 0.27 & $0.07-0.94$ \\
\hline TT-AA & & 0 & 0 & 0 & 0 & & & \\
\hline TT-AT & & 0 & 0 & 1 & 0.2 & & & \\
\hline TT-TT & IIIA/IIIA & 4 & 0.7 & 14 & 2.3 & 0.007 & 0.21 & $0.06-0.70$ \\
\hline sum & & 607 & & 607 & & & & \\
\hline \multicolumn{9}{|l|}{ Sweden } \\
\hline CC-AA & $\mathrm{I} / \mathrm{I}$ & 243 & 68.1 & 378 & 49.8 & & 1.00 & \\
\hline CC-AT & I/IIIB & 27 & 7.6 & 70 & 9.2 & 0.04 & 0.60 & $0.36-0.99$ \\
\hline CC-TT & IIIB/IIIB & 2 & 0.6 & 6 & 0.8 & ns & 0.52 & \\
\hline CT-AA & & 1 & 0.3 & 2 & 0.3 & & & \\
\hline CT-AT & I/IIIA & 74 & 20.7 & 239 & 31.5 & 3.3E-6 & 0.48 & $0.35-0.66$ \\
\hline CT-TT & IIIA/IIIB & 5 & 1.4 & 20 & 2.6 & $\mathrm{~ns}$ & 0.39 & $0.12-1.11$ \\
\hline TT-AA & & 0 & 0 & 0 & 0.0 & & & \\
\hline TT-AT & & 0 & 0 & 1 & 0.1 & & & \\
\hline TT-TT & IIIA/IIIA & 5 & 1.4 & 43 & 5.7 & 0.0001 & 0.18 & $0.06-0.49$ \\
\hline sum & & 357 & & 759 & & & & \\
\hline \multicolumn{9}{|l|}{ Fin + Swe } \\
\hline CC-AA & $\mathrm{I} / \mathrm{I}$ & 725 & 75.2 & 740 & 54.2 & & 1.00 & \\
\hline CC-AT & I/IIIB & 59 & 6.1 & 124 & 9.1 & $1.5 \mathrm{E}-5$ & 0.49 & $0.34-0.68$ \\
\hline CC-TT & IIIB/IIIB & 3 & 0.3 & 8 & 0.6 & ns & 0.38 & $0.08-1.59$ \\
\hline CT-AA & & 2 & 0.2 & 2 & 0.1 & & & \\
\hline CT-AT & I/IIIA & 157 & 16.3 & 402 & 29.4 & $<1.0 \mathrm{E}-6$ & 0.40 & $0.32-0.49$ \\
\hline CT-TT & IIIA/IIIB & 9 & 0.9 & 31 & 2.3 & 0.001 & 0.30 & $0.13-0.65$ \\
\hline TT-AA & & 0 & 0.0 & 0 & 0.0 & & & \\
\hline TT-AT & & 0 & 0.0 & 2 & 0.1 & & & \\
\hline TT-TT & IIIA/IIIA & 9 & 0.9 & 57 & 4.2 & $<1.0 \mathrm{E}-6$ & 0.16 & $0.07-0.34$ \\
\hline sum & & 964 & & 1366 & & & & \\
\hline
\end{tabular}

Table 3

Statistical significance of differences between the protective effects of the class III VNTR genotypes in combined Finnish and Swedish dataset. P-values are calculated using a $2 \times 2$ contingency table (OR $=$ Odds ratio. $95 \% \mathrm{CI}=95 \%$ confidence interval)

\begin{tabular}{lccc}
\hline Fin+Swe & & & \\
VNTR genotype & p-value & OR & $95 \%$ CI \\
\hline I/IIIA vs IIIA/IIIA & 0.02 & 2.47 & $1.15-5.50$ \\
I/IIIA vs IIIA/IIIB & $n s$ & 1.35 & $0.60-3.12$ \\
I/IIIB vs IIIB/IIIB & $n s$ & 1.27 & \\
I/IIIB vs IIIA/IIIA & 0.006 & 3.01 & $1.33-7.02$ \\
IIIA/IIIB vs IIIA/IIIA & ns & 1.83 & $0.59-5.73$ \\
\hline
\end{tabular}

we used allele-specific probes labelled with different lanthanide chelates. This enables the detection of both alleles in one 96-plate well instead of two wells as in the previous method [15].

Conversely to some previous findings [1], our data suggest a stronger protective effect for the more com- mon subclass IIIA (PH) instead of IIIB (VPH). The effect appears also to be genotype-specific since the significance is due to the strong protective effect of the IIIA/IIIA genotype when it is compared to other genotypes containing the class III haplotypes. No significant or otherwise striking difference is found when the other class III genotypes are compared with each other. The significance of the differences seen in the protective effects here can still be considered nominal, especially if the p-values are corrected for multiple testing. Regardless of that, the same magnitude and direction of the protective effects seen in two independent populations could indicate real effects and warrants further studies in bigger cohorts. The variation in the protective effects of the different class III genotypes revealed by the subtyping of the class III lineages suggests that genotyping both $-23 \mathrm{HphI}$ and $-2221 \mathrm{MspI}$ could have 
potential for added specificity and sensitivity in T1D risk estimation in the insulin gene region.

We also detected an unequivocal difference in the frequency of the risk and protective genotypes between the Finnish and Swedish populations although the risk associated with the analyzed genotypes was very similar in both countries. The significant difference in the frequencies of the risk and protective INS genotypes between Finland and Sweden might contribute to the known difference in the incidence of T1D between the two populations (43.9 for Finland, 25.7 for Sweden) [21], although definite claims cannot be made based on the results presented here.

\section{Acknowledgements}

We thank Ms Eija Nirhamo for skillful technical help.

The study was supported by grants from the Juvenile Diabetes Research Foundation and Novo Nordisk Foundation. PerkinElmer Life and Analytical Sciences kindly planned and donated the primers and probes for the INS gene -23 SNP assay.

* The Finnish Pediatric Diabetes Registry and Biobank comprises the following investigators:

Principal Investigator: Mikael Knip (Hospital for Children and Adolescents, Helsinki University Central Hospital)

Steering Committee: Per-Henrik Groop (Folkhälsan Research Institute), Jorma Ilonen (Department of Clinical Microbiology, University of Kuopio and Immunogenetics Laboratory, University of Turku), Jorma Komulainen (Department of Paediatrics, Kuopio University Hospital), Else-Maj Lammi (Hospital for Children and Adolescents, Helsinki University Central Hospital), Raisa Lounamaa (Department of Paediatrics, Central Hospital of Central Finland), Marja-Terrtu Saha (Department of Paediatrics, Tampere University Hospital), Olli Simell (Chair, Department of Paediatrics, Turku University Central Hospital), Ilkka Sipilä (Hospital for Children and Adolescents, Helsinki University Central Hospital), Timo Talvitie (Department of Paediatrics, South Ostrobothnia Central Hospital), Päivi Tapanainen (Department of Paediatrics, Oulu University Hospital), Outi Vaarala (Department of Viral Disease and Immunology, National Public Health Institute)

Locally responsible investigators: Marina von Flittner (Department of Paediatrics, Västra Nyland Hospital), Peter Floman (Department of Paediatrics, Porvoo Hospital), Brage Gustafsson (Department of Paediatrics, Jakobstad Hospital), Maarit Haapalehto (De- partment of Paediatrics, Rauma Hospital), Carita Holm (Department of Paediatrics, Satakunta Central Hospital), Christian Johansson (Department of Paediatrics, Åland Central Hospital), Eero Kaprio (Department of Paediatrics, Peijas Hospital), Tuija Kautto (Department of Paediatrics, Kymenlaakso Central Hospital), Anne Kinnula (Department of Paediatrics, Salo Hospital), Jorma Komulainen (Department of Paediatrics, Kuopio University Hospital), Paavo Korpela (Department of Paediatrics, Kanta-Häme Central Hospital), Pentti Lautala (Department of Paediatrics, Päijät-Häme Central Hospital), Kaija Lindström (Department of Paediatrics, Hyvinkää Hospital), Ulla Niemi (Department of Paediatrics, Lounais-Häme Hospital), Anja Nuuja (Department of Paediatrics, Central Hospital of Central Finland), Päivi Nykänen (Department of Paediatrics, Mikkeli Central Hospital), Seppo Pöntynen (Department of Paediatrics, Central Hospital of Lapland), Anne-Putto-Laurila (Department of Paediatrics, Turku University Central Hospital), Ritva Renko (Department of Paediatrics, South Karelia Central Hospital), MarjaTerttu Saha (Department of Paediatrics, Tampere University Hospital), Juhani Sankila (Department of Paediatrics, Savonlinna Central Hospital), Ilkka Sipilä (Hospital for Children and Adolescents, Helsinki University Central Hospital), Leena Taittonen (Department of Paediatrics, Vaasa Central Hospital), Timo Talvitie (Department of Paediatrics, South Ostrobothnia Central Hospital), Tapani Uotila (Department of Paediatrics, North Karelia Central Hospital), Marita Uro (Department of Paediatrics, Lohja Hospital), Pentti Varimo (Department of Paediatrics, Kainuu Central Hospital), Riitta Veijola (Department of Paediatrics, Oulu University Hospital), Gunilla Wetterstrand (Department of Paediatrics, Jorvi Hospital), Pentti Vuolukka (Department of Paediatrics, Länsi-Pohja Central Hospital), Olli Vuorinen Department of Paediatrics (Central Ostrobothnia Central Hospital)

\section{References}

[1] S.T. Bennett, A.M. Lucassen, S.C. Gough, E.E. Powell, D.E. Undlien, L.E. Pritchard, M.E. Merriman, Y. Kawaguchi, M.J. Dronsfield, F. Pociot, J. Nerup, N. Bouzekri, A. CambonThomsen, K.S. Rønningen, A.H. Barnett, S.C. Bain and J.A. Todd, Susceptibility to human type 1 diabetes at IDDM2 is determined by tandem repeat variation at the insulin gene minisatellite locus, Nature Genetics 9 (1995), 284-292.

[2] B.J. Barratt, F. Payne, C.E. Lowe, R. Hermann, B.C. Healy, D. Harold, P. Concannon, N. Gharani, M.I. McCarthy, M.G. Olavesen, R. McCormack, C. Guja, C. IonescuTirgoviste, D.E. Undlien, K.S. Ronningen, K.M. Gillespie, 
E. Tuomilehto-Wolf, J. Tuomilehto, S.T. Bennett, D.G. Clayton, H.J. Cordell and J.A. Todd, Remapping the insulin gene/IDDM2 locus in type 1 diabetes, Diabetes 53 (2004), 1884-1889.

[3] G.I. Bell, M.J. Selby and W.J. Rutter, The highly polymorphic region near the human insulin gene is composed of simple tandemly repeating sequences, Nature 295 (1982), 31-35.

[4] G.I. Bell, S. Horita and J.H. Karam, A polymorphic locus near the human insulin gene is associated with insulin-dependent diabetes mellitus, Diabetes 33 (1984), 176-183.

[5] J.D. Stead, M.E. Hurles and A.J. Jeffreys, Global haplotype diversity in the human insulin gene region, Genome Res $\mathbf{1 3}$ (2003), 2101-2111.

[6] J.D. Stead, J. Buard, J.A. Todd and A.J. Jeffreys, Influence of allele lineage on the role of the insulin minisatellite in susceptibility to type 1 diabetes, Hum Mol Genet 9 (2000), 2929-2935.

[7] P. Vafiadis, H. Ounissi-Benkalha, M. Palumbo, R. Grabs, M. Rousseau, C.G. Goodyer and C. Polychronakos, Class III alleles of the variable number of tandem repeat insulin polymorphism associated with silencing of thymic insulin predispose to type 1 diabetes, J Clin Endocrinol Metab 86 (2001), 3705-3710.

[8] P. Vafiadis, S.T. Bennett, E. Colle, R. Grabs, C.G. Goodyer and C. Polychronakos, Imprinted and genotype-specific expression of genes at the IDDM2 locus in pancreas and leucocytes, J Autoimmun 9 (1996), 397-403.

[9] S.T. Bennett, A.J. Wilson, F. Cucca, J. Nerup, F. Pociot, P.A. McKinney, A.H. Barnett, S.C. Bain and J.A. Todd, IDDM2VNTR-encoded susceptibility to type 1 diabetes: dominant protection and parental transmission of alleles of the insulin gene-linked minisatellite locus, J Autoimmun 9 (1996), 415421.

[10] A. Pugliese, M. Zeller, A. Fernandez Jr, L.J. Zalcberg, R.J. Bartlett, C. Ricordi, M. Pietropaolo, G.S. Eisenbarth, S.T. Bennett and D.D. Patel, The insulin gene is transcribed in the human thymus and transcription levels correlated with allelic variation at the INS VNTR-IDDM2 susceptibility locus for type 1 diabetes, Nat Genet 15 (1997), 293-297.

[11] P. Vafiadis, S.T. Bennett, J.A. Todd, J. Nadeau, R. Grabs, C.G. Goodyer, S. Wickramasinghe, E. Colle and C. Polychronakos, Insulin expression in human thymus is modulated by INS VNTR alleles at the IDDM2 locus, Nat Genet 15 (1997), 289292.
[12] I. Durinovic-Bello, E. Jelinek, M. Schlosser, T. Eiermann, B.O. Boehm, W. Karges, L. Marchand and C. Polychronakos, Class III Alleles at the Insulin VNTR Polymorphism Are Associated With Regulatory T-Cell Responses to Proinsulin Epitopes in HLA-DR4. DQ8 Individuals, Diabetes 54 (2005), S18-S24.

[13] D. Owerbach and K.H. Gabbay, Localization of a type I diabetes susceptibility locus to the variable tandem repeat region flanking the insulin gene, Diabetes 42 (1993), 1708-1714.

[14] D.E. Undlien, S.T. Bennett, J.A. Todd, H.E. Akselsen, I. Ikaheimo, H. Reijonen, M. Knip, E. Thorsby and K.S. Ronningen, Insulin gene region-encoded susceptibility to IDDM maps upstream of the insulin gene, Diabetes 44 (1995), 620-625.

[15] A.P. Laine, R. Hermann, M. Knip, O. Simell, H.K. Akerblom and J. Ilonen, The human leukocyte antigen genotype has a modest effect on the insulin gene polymorphism-associated susceptibility to type 1 diabetes in the Finnish population, Tissue Antigens 63 (2004), 72-74.

[16] G. Thomson, Mapping disease genes: family-based association studies, Am J Hum Genet 57 (1995), 487-498.

[17] J.R. O'Connell and D.E. Weeks, PedCheck: a program for identification of genotype incompatibilities in linkage analysis, Am J Hum Genet 63 (1998), 259-266.

[18] J. Graham, W.A. Hagopian, I. Kockum, L.S. Li, C.B. Sanjeevi, R.M. Lowe, J.B. Schaefer, M. Zarghami, H.L. Day, M. Landin-Olsson, J.P. Palmer, M. Janer-Villanueva, L. Hood, G. Sundkvist, A. Lernmark, N. Breslow, G. Dahlquist and G. Blohme, Genetic effects on age-dependent onset and islet cell autoantibody markers in type 1 diabetes, Diabetes 51 (2002), 1346-1355.

[19] M. Sjöroos, A. Iitiä, J. Ilonen, H. Reijonen and T. Lövgren, Triple-label hybridization assay for type-1 diabetes-related HLA alleles, Biotechniques 18 (1995), 870-877.

[20] S. Nejentsev, M. Sjöroos, T. Soukka, M. Knip, O. Simell, T. Lövgren and J. Ilonen, Population-based genetic screening for the estimation of Type 1 diabetes mellitus risk in Finland: selective genotyping of markers in the HLA-DQB1. HLADQA1 and HLA-DRB1 loci, Diabet Med 16 (1999), 985-992.

[21] A. Green and C.C. Patterson, Trends in the incidence of childhood-onset diabetes in Europe 1989-1998, Diabetologia 44(Suppl 3) (2001), B3-B8. 


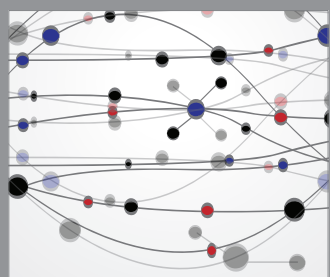

The Scientific World Journal
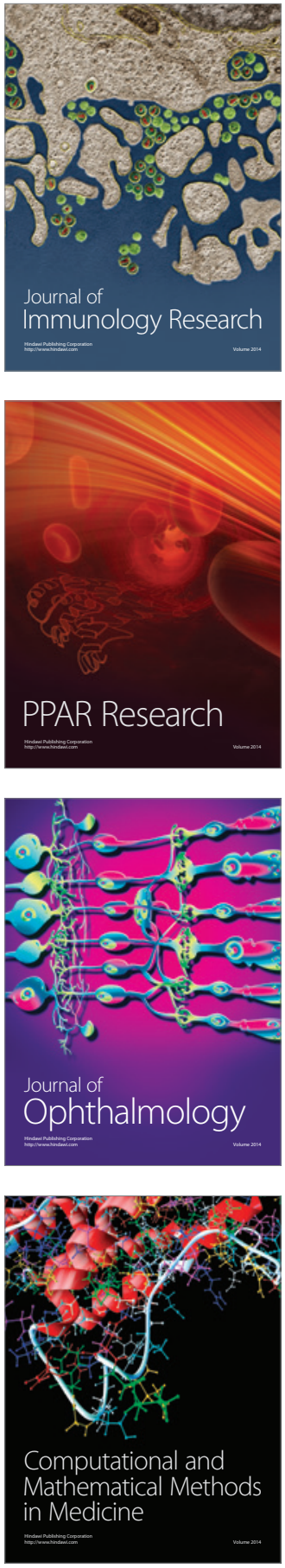

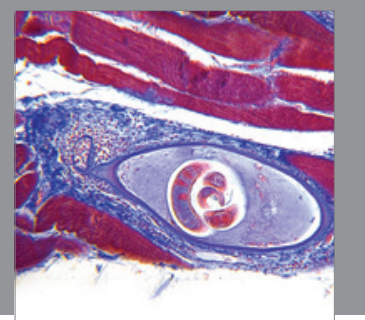

Gastroenterology

Research and Practice
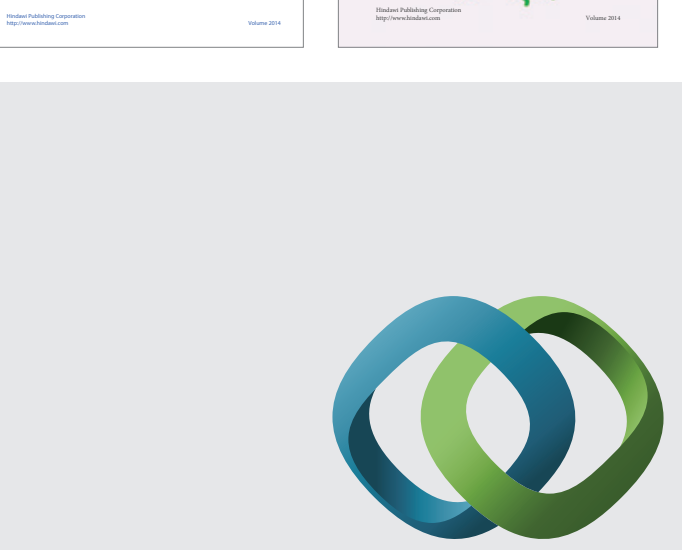

\section{Hindawi}

Submit your manuscripts at

http://www.hindawi.com
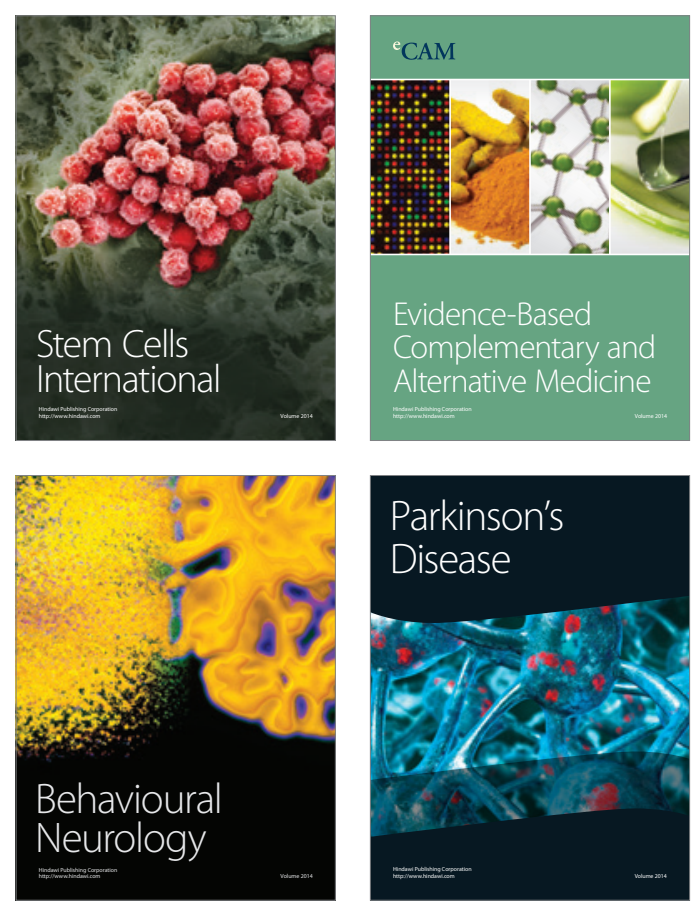

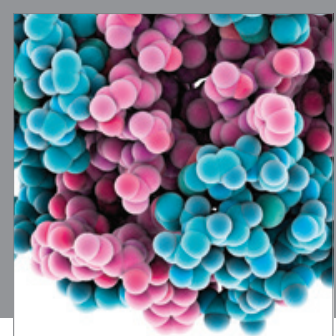

Journal of
Diabetes Research

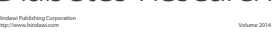

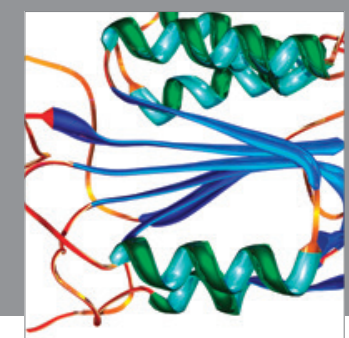

Disease Markers
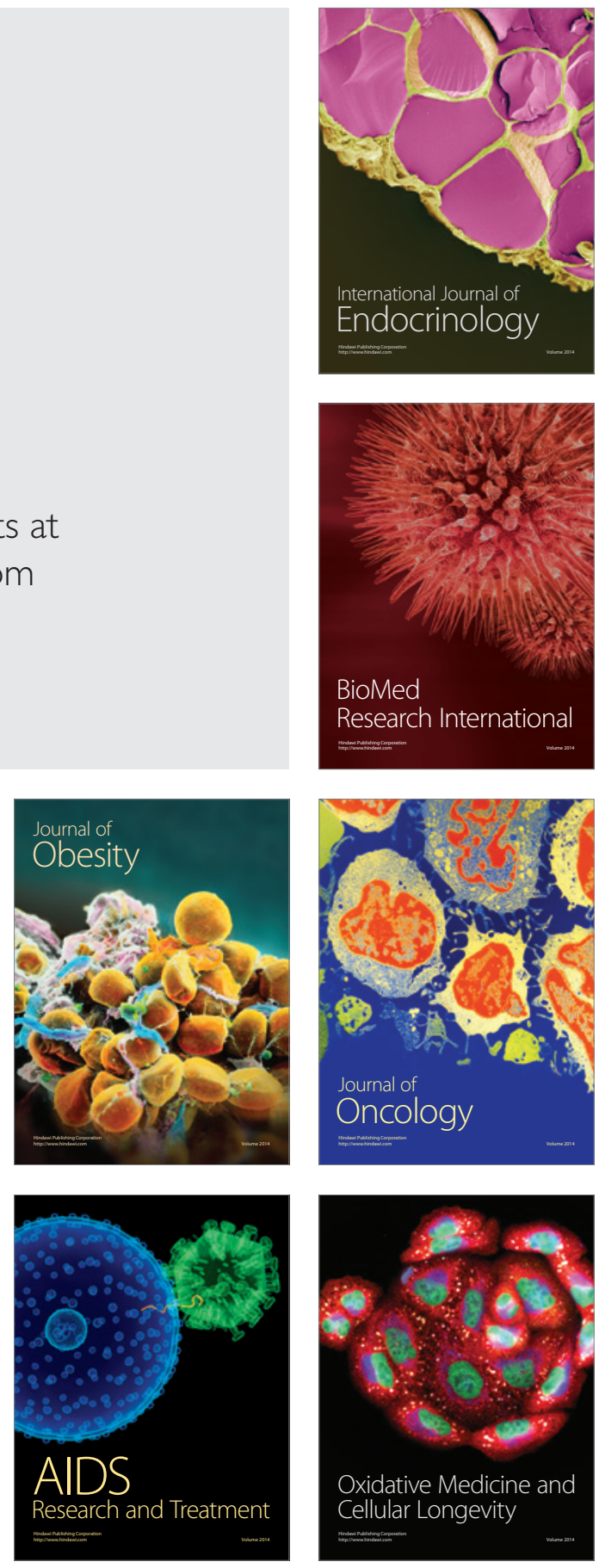